\title{
EDUCATION AND TRAINING OF THIRD WORLD GEOSCIENTISTS
}

by

\section{P. Gerald Cooray}

Third World geoscientists generally have to undertake varied duties and the demand for specialists is relatively limited. The emphasis in geoscientific education should therefore be on 'pure' geology and on the basic applied aspects of the science. This article is based on the author's first-hand personal experiences and observations; it highlights some of the educational deficiencies plaguing the development of Third World geoscience and offers some practical solutions.

\section{The Successes}

\begin{abstract}
A basic assumption in this appraisal is that the economic and social development of most Third World countries is such that their primary need is for good, 'all-round' geologists who can be called upon to perform a variety of duties, and who can eventually be trained for specialist functions as the need arises.
\end{abstract}

With this premise in mind, one can attempt to assess the success and failures of the current systems of education and training in the Third World. It is obviously not possible to generalize, although it is fair to say that in spite of many difficulties, certain Third World countries have gone a long way toward training the kind of geoscientists that are needed by them. Others have fallen far short of the ideal.

At present, graduates in several Third World countries have acquired, in just three to four years' time, a sound knowledge of mineralogy, petrology, geomorphology, structural geology, photogeology, stratigraphy and economic geology, and a fair understanding of the basic principles and practices of exploration geophysics, exploration geochemistry, hydrogeology and engineering geology. These subjects form the fundamental core of their educational program; options for follow-up study of a particular subject in greater depth in the final year are also available.

Of particular significance in these programs is the emphasis on:

a) geological mapping methods - through mapping classes and independent mapping exercises, the latter generally under supervision and for lengths of time varying from 4 to 8 weeks;

b) the elements of research - through special projects such as field and/or laboratory investigations, compilations, literature reviews;

c) the presentation of data - both orally and through the writing of reports; and

d) practical training - through assignments with geological surveys, exploration companies and mines during vacation periods. (One geoscience department even treats this period of practical training as a prerequisite for graduation.)

There is too often a tendency to lose sight of these successes when considering some of the educational difficulties and failures in the Third World. It should be stressed at the outset, then, that the competence of many of the successful Third World geoscientists has in no small measure been due to the kind of education and training they received as undergraduates.

\section{The Deficiencies}

One of the single biggest handicaps to adequate geoscientific education in the Third World has been the students' poor background knowledge of mathematics and the physical sciences. This is largely a heritage of the inadequate teaching of these subjects at the secondary school level. The reasons for it are well known - not enough teachers, outdated methods, lack of textbooks and equipment.

Some Third World universities have recognized this deficiency and have introduced a pre-university year into the curriculum which attempts to raise the student's underEPISODES, Vol. 1981, No. 2. standing of these subjects to a certain level before they embark on the undergraduate program itself - a practical solution to the problem. Others have argued that a comprehensive understanding of mathematics, physics and chemistry is not really necessary for the education of geoscientists, but then one wonders how a potential geoscientist can be expected to understand anything of modern structural geology, mineralogy or petrology (to say nothing of engineering geology, hydrogeology or geophysics) without this fundamental base.

Another major difficulty is that many Third World countries still suffer from a shortage of indigenous teaching and technical staff, and have to rely to varying extents on nonnationals. As a result, such departments suffer from a lack of stability and continuity: rapid turnover of expatriate staff, changes in curricula and syllabi, in supervision of students, in staff/student contacts, interruptions in the use and maintenance of research and teaching equipment, are all too frequent.

It is more common now to see nationals teaching in some of the Third World universities. Often, however, these (as other geoscientists in key positions) were the early, but not necessarily the most competent, graduates. This tends to affect the progress of some of the younger (and often brighter) graduates adversely. One might also add that universities outside the Third World which are less demanding when granting post-graduate degrees to Third World nationals than they are with their own nationals are partially to blame. The feeling that rules and standards may be relaxed to accommodate such students leads to disastrous long-term results.

Attitudinal problems plague the training of technical staff. Unfortunately, candidates in the Third World with even the bare minimum qualifications for entering a university want to obtain a degree, irrespective of whether or not they have the aptitude. The material rewards seem to be greater for the graduate with a degree than for a technician - or so it seems. Moreover, to some classes of educated people in the Third World, becoming a technician, even a superior one, is considered beneath their dignity. Before these attitudes can be overcome, a concerted effort must be made to raise the status and the emoluments of technical staff in the Third World.

For those who do choose a technical career, the avenues and means for training are severely limited. One solution lies in the establishment of regional training institutes, or even regional training courses, where instruction is given in such practical matters as the maintainence and repair of geophysical, analytical, electronic equipment, and not just in thin-section preparation.

Many countries of the Third World, because of their depressed economic situation, suffer from a chronic shortage of foreign exchange and exist on foreign loans and aid of one sort or another. Universities in turn suffer because they lack the foreign exchange required to purchase essential equipment, books and journals. One has to live with the subsequent frustrations that both staff and students suffer to 



Structural geology class in session, Geology Department, University of Zambia.

really appreciate the harmful effects that this can have on geoscientific education. Gifts of 'surplus literature' by universities in the more affluent countries have been helpful, but this is not really a solution to the problem, partly because of the suspicion that 'surplus' literature is really 'outdated' literature that has outlived its usefulness to the donors, partly because the scheme is not fully systematized or comprehensive. It could, for example, include rock and mineral collections, thin and polished sections, fossil collections, maps, and the like. Third World geoscience departments could also help each other by gift donations and exchange of material within their own regions. Such material could be more relevant to their particular needs.

Language, as a medium of instruction and communication, has of ten been mentioned as one of the key problems in Third World countries. Primary and secondary courses are generally conducted in the language of the country and little or no attention is paid to a second (international) language. While attempts have been made to continue using the national language at the tertiary level of education, they have not been very successful, particularly in the fields of science and medicine, owing largely to the lack of textbooks and even of terminology in the language, a shortage of competent teachers knowing the national language, and the inability of students to read the current literature. The conflict between political expediency, which demands the use of the national language, and practical necessity, which requires knowledge of at least one international language, defies easy solution. The debate between proponents of the use of national languages for all instruction and communication in spite of the burdens that this might place on teachers and the insularity of outlook that might develop, and the proponents of a fullscale intensive teaching effort in a second (international) language, continues.

Educational systems in Third World countries generally tend to be too lecture-oriented, with far too little attention being paid to practical work. As a result, students are of ten said to possess a high degree of theoretical knowledge but are sometimes ignorant of even its most elementary applications. of course, project-oriented teaching methods can only be carried out effectively if the necessary aids to such teaching are available.

One might stress also that the teacher's responsibility does not end when the student has earned a degree; it should continue for a few years, until the student 'finds his feet'. In the Third World many graduates return again and again to their teachers for advice and guidance. One area where it is likely to be sought is in the field of publications. With EPISODES, Vol. 1981, No. 2. printing costs being fairly exorbitant around the world, most established journals will not accept for publication material that is regional and local in scope, in spite of the fact that it is these very regional studies of the Third World that are most needed today for these are the least known parts of the earth. Very few developing countries have their own geoscientific journals - and those that exist of ten appear irregularly or have a limited circulation. The young graduate thus has little opportunity to publish his work and to debate it with the 'outside' world. If he is very fortunate, he may get to an international seminar or conference - perhaps with the aid of an organization such as AGID or Unesco - and so present his views there. But few get that opportunity. When countries lack foreign exchange for the essentials of life, they are not likely to finance trips for junior geoscientists; if anyone is sent it is more likely to be the geoscientific administrator or the 'geopolitician'.

The problem of intellectual isolation and academic inbreeding is a very real one in the Third World. There is lack of contact with other workers in a particular field of interest, lack of opportunity to hear the 'giants' of geoscience deliver a paper, or to discuss the latest concepts or theories in a particular field. This can be psychologically and intellectually devastating.

Consulting and contracting organizations working in Third World countries have generally shown a lack of real concern with 'counterpart training', that is, systematically passing on their knowledge and expertise to national geoscientists.

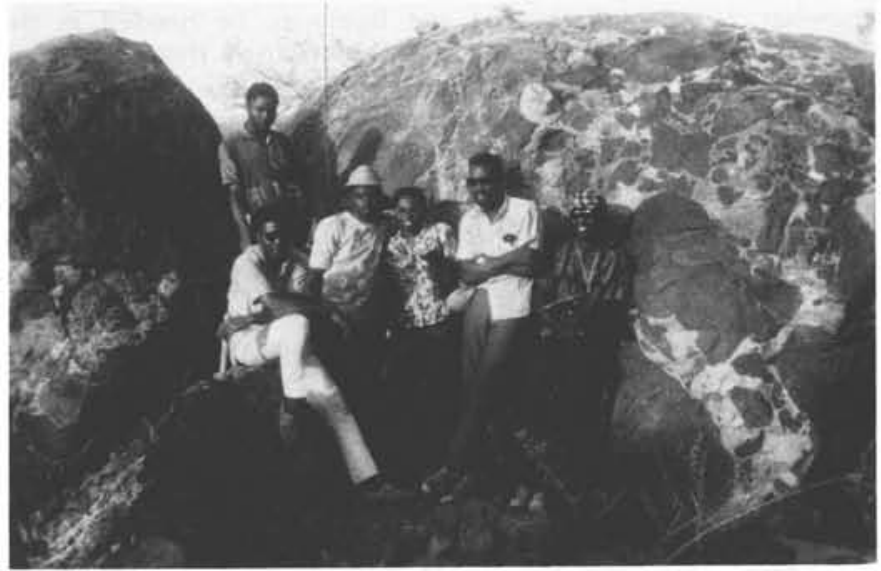

Group of final year students in the field at Pankshin, Jos Plateau, Nigeria. 
Third World governments themselves have been remiss not to insist on having counterpart training written into the contracts, or in ensuring that it is carried out. Again, solutions here lie in attitudinal or philosophical changes.

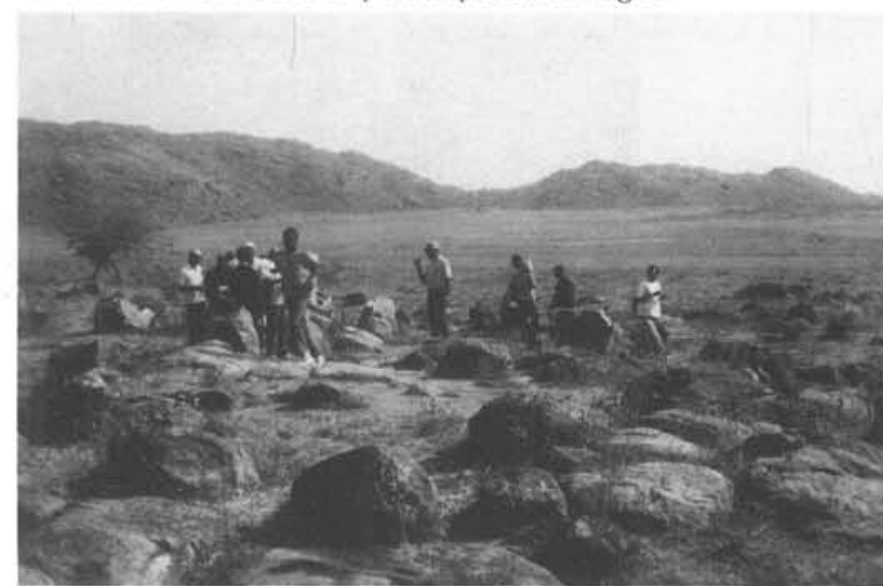

Geology students from the University of If e, Nigeria examine hornblende-fayalite granite in a ring dyke complex, Jos Plateau, Nigeria.

\section{Too Many Geoscientists?}

It has been suggested that the Third World countries are possibly turning out too many geoscientists and that those that we have are underutilized. If this were so, it would surely be due to such factors as lack of direction and guidance, lack of funds for field work, frustration from bureaucratic hindrance, and an unawareness of the true functions of the geoscientist. Obstacles such as these can be removed by a concerted effort on the part of the geoscientific community to educate administrators and the public alike in the very real contribution that geoscience and geoscientists can make to national development and growth.

As a corollary to the above, some believe that the Third World countries should conduct manpower surveys before proceeding much further with geoscientific education and training. Any move to curtail or restrict the number of geoscientists being educated and trained in the Third World should be opposed. Given the current pace of development of geoscientific concepts and their applications, it is impossible to predict how many geoscientists a country will need in the next decade. Geoscientific education and training should be made available to all who want it, for there is no better training for a proper understanding and appreciation of the dangers of exhausted resources and polluted environment and other very significant problems of our age.

Furthermore, geoscientists in the Third World should be encouraged to go into teaching, management, administration, public relations, or any other sphere of public life. Where manpower surveys might assist us is in determining the number of specialists that are likely to be needed in the coming years, or in guiding the selection of those to whom specialized training should be given.



Geology students from the University of If e, Nigeria.

EPISODES, Vol. 1981, No. 2.

\section{Conclusion}

It is generally accepted that geoscientific education and training in Third World countries should be as broadly based as possible. It should have a sound foundation in the core subjects of 'pure' geology, and adequate coverage of the basic principles and methods of applied geology, modified and adapted to local needs and conditions. Specialization is not necessary or desirable at the undergraduate level; it can be acquired through post-graduate study, in-service training, workshops, training courses or other similar methods. This view has also been supported, for example, by those concerned with training engineering geologists (Dearman and Oliveira, 1978; Knill, 1975).

In appraising the strengths and weaknesses of current geoscientific education in the Third World, one would do well to address some of the following fundamental questions.

- Are we in tine Third World in fact turning out the kinds of geoscientists that are needed by us in our varying situations?

- Are the existing patterns of education and training the correct ones, or do we need to rethink these patterns and make drastic changes, if necessary?

- Should we have a multiplicity of courses and give the student wide latitude in the choice of options, or should we severely restrict this choice?

- Should there be room in our programs for such subjects as natural resource management, economics, political and social sciences, management techniques?

- If so, how do we fit them into already over-crowded programs - and at the expense of what?

- Do we continue with the present general policy of producing graduates with a sound, broad-based geoscientific education, leaving specialization to the post-graduate stage, or should we begin to produce graduates with degrees in hydrogeology, engineering geology, applied geology?

- Should we not be monitoring our programs and teaching methods, and assessing or evaluating our achievements?

\section{References}

Dearman, W.R., and Oliveira, R. (eds.), 1978, IAEG Commission on Teaching and Training in Engineering Geology. Final Report (October 1978): Bull. Int. Assoc. Engineering Geol., no. 18, p. 9-14.

Knill, J.L., 1975, An introduction to engineering geology: Ground Engineering, v. 8, no. 2, p. 31-34.

\section{ABOUT THE AUTHOR:}

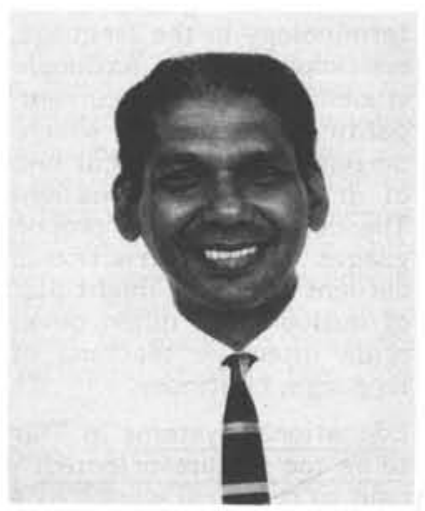

Professor P. Gerald Cooray is on staff at the Faculty of Earth Sciences, King Abdulaziz University, Jeddah, Saudi Arabia. After a career of several years as a field geologist in the Geological Survey of Sri Lanka (Ceylon), he was successively Head of the Geology Department, University of Ife, Nigeria, and Head of the Geology Department and Dean of the School of Mines, University of Zambia, Lusaka, before taking up his current appointment. He is a member of the Council of AGID, an affiliated association of IUGS, a member of the Scientific Committee of IGCP, and a member of the IUGS Commission on Geology Teaching. 